\title{
Exploring Creative Tourism Based on the Cultural and Creative Cities (C3) Index and Using Bootstrap Confidence Intervals
}

\author{
Mercedes Mareque ${ }^{1}$ (1) , Elena de Prada Creo ${ }^{2, *}$ and Marcos Álvarez-Díaz ${ }^{3}$ \\ 1 Department of Financial Economics and Accountancy, University of Vigo, 32004 Ourense, Spain; \\ chedesmareque@uvigo.es \\ 2 Department of English, French and German Philology University of Vigo, 32004 Ourense, Spain \\ 3 Department of Fundamental Economics, University of Vigo, 32004 Ourense, Spain; marcos.alvarez@uvigo.es \\ * Correspondence: edeprada@uvigo.es
}

\section{check for} updates

Citation: Mareque, M.; de Prada Creo, E.; Álvarez-Díaz, M. Exploring Creative Tourism Based on the Cultural and Creative Cities (C3) Index and Using Bootstrap Confidence Intervals. Sustainability 2021, 13, 5145. https://doi.org/ $10.3390 /$ su13095145

Academic Editors:

Valentina Montalto, Pier Luigi Sacco and Michaela Saisana

Received: 29 March 2021

Accepted: 29 April 2021

Published: 4 May 2021

Publisher's Note: MDPI stays neutral with regard to jurisdictional claims in published maps and institutional affiliations.

Copyright: (c) 2021 by the authors. Licensee MDPI, Basel, Switzerland. This article is an open access article distributed under the terms and conditions of the Creative Commons Attribution (CC BY) license (https:// creativecommons.org/licenses/by/ $4.0 /)$.

\begin{abstract}
Creative tourism is a novel segment of the tourism market that may turn into a great opportunity for small cities to attract visitors. Thus, it can be a possible economic and social driver for local development. Despite its potentiality, not much empirical research has been conducted to explore the specific strengths and weaknesses of developing creative tourism in small cities, probably due to the lack of reliable data. Our study aims to fill this gap by using the C3 Index, a composite indicator developed by the Joint Research Center-European Commission, as the data source, and the bootstrap method as a statistical tool to detect significant differences between small and large cities. Our findings reveal that the smallest cities show positive features to foster creative tourism (e.g., they have at least as good cultural infrastructures and cultural participation as the largest cities). However, in some other aspects, small cities still have room to improve (e.g., improvements in local and international connections or further development of the cultural and creative sector).
\end{abstract}

Keywords: creative tourism; small cities; C3 Index; bootstrapped confidence intervals

\section{Introduction}

Creative tourism has been approached and developed from many different perspectives. Although academia has not reached an agreed definition, there are some concepts such as active participation, authenticity, interaction, self-realization, or memorability that are commonly shared [1]. To put it in Richards and Raymond's words, creative tourism is a type of tourism "which offers visitors the opportunity to develop their creative potential through active participation in learning experiences which are characteristic of the holiday destination where they are undertaken" [2]. By focusing on non-traditional uses of the cultural potential of destinations, creative tourism tries to overcome the problems of overdevelopment, lack of investments, overcrowding, homogenization, and lack of uniqueness that cultural tourism has been suffering in the last years. Despite the increasing interest in creative tourism over the last decades, there are still many gaps limiting its enormous potential. Equally, they evidence the need for further research that could be highly relevant for the strategic planning of tourism destinations. From an economic point of view, creative tourism has been considered a development tool to improve national economies, regions, and cities, stimulate local development, and avoid the exodus of young people, depopulation, and lack of economic resources [3,4]. It can become an essential economic driver for the local economy, with an increase of start-ups and spinoffs in creative industries [5]. Having an in-depth knowledge of the features, factors, and variables associated with culture and creativity is fundamental to make well-grounded decisions to improve the cultural and creative potential of urban areas. However, the still limited research and the lack of tools to observe data from different perspectives have been hindering the correct evolution towards effective creative tourism formulas and provoking the risk of adopting serial reproduction models instead of fostering their distinctive resources, especially in 
the case of small cities [6]. In this sense, the Cultural and Creative Cities (C3) Monitor constitutes a powerful tool to bridge the gap and solve this problem, as it provides the necessary information to study, explore, measure, and compare valuable data. It offers a detailed and comprehensive source of information about different types of culturally and creatively relevant European cities. In addition, and contrary to other existing measures, the C3 monitor provides not only a relevant set of analyzable cultural and creative dimensions, but also a transparent measurement framework that can be retrieved in different formats, from raw research data to user-friendly web displays. The data and the various possibilities of establishing different relationships among the variables can be of great interest for researchers, decision-makers, creative workers, investors, creative travelers, and entrepreneurs, who can find insightful details about city improvement, new business ventures, and opportunities.

The main objective of our research is to analyze the potential development of creative tourism in European small cities. Although it was initially thought that large cities and their population concentration and diversity favored creativity, recent research has shown that the population of cities does not necessarily affect their creative pulse, and in some cases, smaller cities can surpass larger ones in some aspects [7,8]. From the point of view of creative tourism, small cities present many advantages, as they can easily meet the necessary requirements that creative tourism demands. Additionally, although small cities normally lack the grandeur of larger ones, they have unique heritage and traditions-both tangible and intangible- that can be enhanced with a compelling story in a context of authenticity and absence of overcrowding. In turn, creative tourism benefits the sustainable growth of small cities, protecting their eco-friendly quality of life [9]. The potential of small cities should be especially considered in Europe, as approximately $60 \%$ of the population live in small $(40 \%$ in the range $10,000-50,000)$ or medium-sized urban areas $(20 \%$ in the range 50,000-250,000). Additionally, there is a reverse migration flow from big cities to small urban areas [10].

To carry out our study, we use data obtained from a complementary tool of the C3 Monitor: the Cultural and Creative Cities (C3) Index [8]. This composite indicator provides a synthetic measure of a city's cultural and creative performance: the higher the score, the higher the performance of the city. From the classification defined in Montalto et al. [8], we also implement the bootstrap method to infer whether the score of the index (or any of its components) reached by small cities is statistically different from larger cities. This inferential analysis may be of great help to detect potential characteristics of improvement in the development of creative tourism in small cities.

Our paper is organized as follows: after this introductory section, Section 2 briefly describes the data (i.e., the C3 Index and its conceptual framework) and the bootstrap methodology. In Section 3, we present the main results of our study. Finally, we conclude in Section 4.

\section{Data and Methodology}

\subsection{Data}

The data used in our study come from the information contained in the 2019 C3 Monitor, and specifically in the C3 Index. The C3 Index is a composite indicator that measures the cultural and creative performance of 190 cities in 30 European countries (the EU-27 plus the United Kingdom, Norway, and Switzerland). It is developed by the Joint Research Center, the in-house research center of the European Commission, according to the statistical recommendations given in Nardo et al. [11].

The C3 Index is composed of twenty-nine indicators, nine dimensions, and three sub-indices that represent the main aspects of the cities' cultural, social, and economic vitality: "Cultural Vibrancy", "Creative Economy", and "Enabling Environment". The weighted average of these three sub-index scores gives the overall measure of the city's cultural and creative performance: the higher the score, the higher the performance of the city. Table 1 describes the theoretical framework of the C3 Index at the level of the 
index, sub-indices, and dimensions. A more detailed description of the theoretical framework and an exhaustive technical explanation on how the C3 Index was designed can be found in Montalto et al. [8] and Montalto et al. [12]. The whole data can be downloaded at https: / / composite-indicators.jrc.ec.europa.eu/cultural-creative-cities-monitor/docsand-data (accessed on 24 November 2020).

Table 1. Theoretical framework of the C3 Index: the C3 index, sub-indices, and dimensions.

\begin{tabular}{|c|c|c|c|c|c|c|c|c|}
\hline \multicolumn{9}{|c|}{ C3 INDEX } \\
\hline \multicolumn{2}{|c|}{ 1. Cultural Vibrancy } & \multicolumn{3}{|c|}{ 2. Creative Economy } & \multicolumn{4}{|c|}{ 3. Enabling Environment } \\
\hline $\begin{array}{c}\text { D.1.1 } \\
\text { Cultural } \\
\text { Venues and } \\
\text { Facilities }\end{array}$ & $\begin{array}{c}\text { D.1.2 } \\
\text { Cultural } \\
\text { Participation } \\
\text { and Attrac- } \\
\text { tiveness }\end{array}$ & $\begin{array}{c}\text { D.2.1 } \\
\text { Creative and } \\
\text { Knowledge- } \\
\text { based } \\
\text { Jobs }\end{array}$ & $\begin{array}{c}\text { D.2.2 } \\
\text { Intellectual } \\
\text { Property and } \\
\text { Innovation }\end{array}$ & $\begin{array}{c}\text { D.2.3 } \\
\text { New Jobs in } \\
\text { Creative } \\
\text { Sectors }\end{array}$ & $\begin{array}{c}\text { D.3.1 } \\
\text { Human } \\
\text { Capital and } \\
\text { Education }\end{array}$ & $\begin{array}{l}\text { D.3.2 } \\
\text { Openness, } \\
\text { Tolerance } \\
\text { and Trust }\end{array}$ & $\begin{array}{c}\text { D.3.3 } \\
\text { Local and } \\
\text { International } \\
\text { Connections }\end{array}$ & $\begin{array}{c}\text { D.3.4 } \\
\text { Quality of } \\
\text { Governance }\end{array}$ \\
\hline
\end{tabular}

As reflected in Montalto et al. [8], the C3 Index is a useful tool for policymakers to plan efficient cultural strategies. In fact, it has already been used to design policies by local governments across Europe (e.g., Bologna, Edinburg, Geneva, Győr, Leeuwarden, and Madrid). In recent years, the C3 Index has also become a valuable tool for conducting robust scientific studies on culture. For instance, Montalto et al. [12] describe the C3 Monitor database and use it to analyze the role of culture and as a resource for development. Stipanović et al. [13] use the C3 Index to analyze the role of culture and creative industries to strengthen urban tourism to the city of Rijeka, Croatia. Montalto et al. [14] employ the 3C Monitor to foresee how Brexit is going to affect the UK's creative economy at an urban level. De Jorge-Moreno and De Jorge-Huertas [15] perform a benchmark analysis of European cities based on the estimate on of a composite index of efficiency using the 3C Monitor. Van Puyenbroeck et al. [16] carry out a similar analysis to identify city-specific strengths. More research using the information contained in the $3 \mathrm{C}$ Index is expected in the future.

Our analysis primarily relies on the classification reported in Montalto et al. [8] and Van Puyenbroeck et al. [16]. Specifically, they classify cities according to their level of population, GDP per capita, employment, and regional development. The group thresholds in each classification were determined by using a data clustering method to determine the best arrangement of values into the different groups. Table 2 shows the different city classifications and their corresponding groups. In our study, we focus on the population classification to analyze the potential development of creative tourism in European small cities. The list of the cities included in the analysis can be found in Annex E "Dataset compiled for the Cultural and Creative Cities Monitor (2019 edition)" available online at https: / / composite-indicators.jrc.ec.europa.eu/cultural-creative-cities-monitor/docsand-data (accessed on 24 November 2020).

Table 2. City classifications and groups.

\begin{tabular}{|c|c|c|c|c|c|c|}
\hline Group & & Population & & $\begin{array}{l}\text { GDP (In } \\
\text { Euros) }\end{array}$ & $\begin{array}{l}\text { Employment } \\
\text { Rate }\end{array}$ & $\begin{array}{l}\text { EU Cohesion } \\
\text { Policy Regions }\end{array}$ \\
\hline 1 & XXL & $\begin{array}{c}\text { Extra, } \\
\text { Extra-Large }\end{array}$ & $>1$ million & $>45,000$ & $>79 \%$ & Less developed \\
\hline 2 & $\mathrm{XL}$ & Extra-Large & $\begin{array}{l}500,000-1 \\
\text { million }\end{array}$ & $35,000-45,000$ & $75-79 \%$ & Transition \\
\hline 3 & $\mathrm{~L}$ & Large & $250,000-500,000$ & $27,000-35,000$ & $70-75 \%$ & $\begin{array}{c}\text { More } \\
\text { developed }\end{array}$ \\
\hline 4 & $\begin{array}{l}M \\
S\end{array}$ & Medium & $100,000-250,000$ & $19,000-27,000$ & $\begin{array}{l}63-70 \% \\
<63 \%\end{array}$ & \\
\hline
\end{tabular}




\subsection{The Bootstrapped Confidence Interval}

Confidence intervals have been commonly used in hypothesis testing because of their great intuitive appeal [17]. The approximation traditionally adopted in econometrics usually relies on asymptotic theory; however, the advances in computing have enabled the significant development, improvement, and intense use of non-parametric techniques such as bootstrapping. During the last decades, researchers from diverse fields have incorporated bootstrapping into their toolbox to solve different problems, including statistical hypothesis testing [18].

Bootstrapping is a non-parametric method that uses random sampling with replacement to estimate the empirical distribution of almost any statistic, including the mean. In our study, we use the bootstrapping technique to construct confidence intervals that allow us to accept or reject the null hypothesis of equality of means. The main advantage of the bootstrap method lies in the fact that it allows us to empirically construct confidence intervals without making a priori any assumptions regarding the theoretical statistical distribution of the statistic. Moreover, as pointed out by Brownstone and Valletta [19], bootstrapping intervals have the additional advantage of not being symmetric (i.e., they can be longer on the left or right).

Specifically, we estimate bootstrapped confidence intervals to test the null hypothesis

$$
H_{0}: \mu_{i, C}^{I}=\mu_{j, C}^{I}
$$

where $\mu_{i, C}^{I}$ and $\mu_{j, C}^{I}$ are the means of a specific indicator $I$ (i.e., the C3 Index or each one of its components) in the city group $i$ and $j$ belonging to the classifications $C$. In total, we have $I=13$ indicators (the C3 Index, three sub-indices, and nine dimensions), $C=4$ classifications (level of population, GDP, employment, and regional development) and five city groups for each classification (except for the classification according to the EU Cohesion Policy Regions, where there are only three groups: less-developed regions, transition regions, and most developed regions). To illustrate this with an example, if we look at the classification according to the level of population, we have five possible groups: from group 1 (the extra, extra-large city group that comprises the cities with more than one million inhabitants) to group 5 (the small city group that contains cities with a population between 50,000 and 100,000 inhabitants). $H_{0}: \mu_{1, \text { population }}^{I}=\mu_{5, \text { population }}^{I}$ is the null hypothesis that tells us that the mean of the indicator $I$ for the cities sorted in group 1 is equal to the mean of the cities placed in group 5 . The bootstrapped confidence intervals for $\mu_{1, p o p u l a t i o n}^{I}$ and $\mu_{5, \text { population }}^{I}$ allow us to test if these means are statistically different: if the confidence intervals do not overlap, then we can reject the null hypothesis of equal mean $\left(H_{0}: \mu_{1, \text { population }}^{I}=\mu_{5, \text { population }}^{I}\right)$ at a specific level of significance.

To implement the bootstrapping, we followed the indications given in Martínez and Martínez [20]. The procedure was conducted in MATLAB 2020b to estimate bootstrapped confidence intervals according to the following 10 steps: First step: we chose one of the classifications $(C)$ given in Table 2 (e.g., population). Second step: we chose one indicator I given in Table 1 (e.g., the C3 index score). Third step: we chose the $i$ city group (e.g., group 1: cities with more than one million inhabitants). We calculated the mean of the selected indicator $I$ for this city group. Fourth step: from the original sample, we generated a bootstrap sample by resampling the values of the indicator with replacement. The bootstrap sample has exactly the same size as the original sample (190 observations). We computed the mean of the bootstrap sample. Fifth step: we repeated the fourth step B times to get $B$ means for the selected indicator $I$. These $B$ values allowed us to determine the empirical sampling distribution of the arithmetic mean. At this point, a crucial task to be solved as how to set an optimal value for B. As Mooney and Duval [21] point out, high values of $B$ enable the bootstrap method to approximate the true statistical distribution of the statistic more successfully. Efron and Tibshirani [22] state that $B=1000$ replications are enough to have satisfactory results. In our study, we determined a higher number of replications $(B=10,000)$ to ensure a good approximation, taking into account that the 
computational cost was not excessively high. Sixth step: Once we had the bootstrapping empirical distribution of the arithmetic mean for the selected indicator, the following step was to construct a reliable confidence interval. The specialized literature offers many procedures to build bootstrap confidence intervals, the most common being the normal method, the percentile method, the percentile t-method, the bias-corrected percentile method, and the accelerated bias-corrected (Bca) method. Mooney and Duval [21] and Briggs et al. [18] provide a full description of all these methods, as well as the advantages and disadvantages of each one of them. In our study, we applied the accelerated biascorrected (Bca) method for several reasons. First, it is the most recommended method for general use [22]. Second, the Bca method is capable of producing highly accurate confidence intervals from a bootstrap distribution [17]. Finally, it performs better than other methods under a wider variety of assumptions [18]. Seventh step: we repeated steps 3 to 6 , but choosing another group $j(j \neq i)$ of the same classification (e.g., group 2: cities with more than 500,000 and less than one million inhabitants). Eighth step: the estimated bootstrapping confidence intervals can be used to generalize the standard null hypothesis testing of equal arithmetic means of the indicator $I$ for the groups $i$ and $j$ belonging to the same classification $\mathrm{C}\left(H_{0}: \mu_{i, C}^{I}=\mu_{j, C}^{I}\right)$. In particular, the rule of decision was that if the estimated bootstrap confidence intervals of two means do not overlap, then we could conclude that they differ for the significance level chosen to compute the interval (the level of confidence in our case was determined at 95 percent). That is, we had statistical arguments to reject the null hypothesis. Otherwise, if the intervals overlapped, we accepted it. Ninth step: we repeated steps 2 to 8 , but choosing another indicator $I^{\prime}$ (e.g., the Culture Vibrancy score). Tenth step: we chose another classification $C^{\prime}$, different to the previous one (e.g., the classification according to the levels of GPD), and we repeated steps 2 to 9 .

At the end of the process described in the steps 1 to 10, we have bootstrapped confidence intervals of the means for all indicators of all city groups belonging to the different classifications described in Table 2. These confidence intervals will allow us to accept or reject the null hypothesis of equal arithmetic mean for the city groups of the same classification.

\section{Results and Discussion}

\subsection{General Overview}

In Table 3, we present the average score and its corresponding bootstrapped confidence intervals for the C3 Index and its components, according to the population classification. In Appendix A, we report the same information, but for other classifications. In general, we observe a positive relationship between the scores of the C3 Index (and its components) and the levels of GDP per capita, regional development, employment, and population.

Focusing on Table 3, a simple comparison among groups indicates that the smallest cities perform mostly worse than the largest cities. For instance, on average, the extra, extra-large cities have a C3 Index score statistically higher than the smallest cities (the bootstrapped confidence intervals do not overlap). The extra, extra-large cities show statistically higher scores in the sub-indices "Creative Economy" (D2.1 Creative \& Knowledge-based Jobs, D2.2 Intellectual Property \& Innovation, and D2.3 New Jobs in Creative Sectors), and "Enabling Environment" (D3.3 Local \& International Connections). There are no statistical differences for the sub-index "Cultural vibrancy", although it is interesting to note that for the dimension "D1.1 Cultural Venues \& Facilities" the smallest cities present a statistically significant higher score. 
Table 3. Population groups: Average scores and bootstrapped confidence intervals for the 2019 C3 Index, its sub-indices, and dimensions.

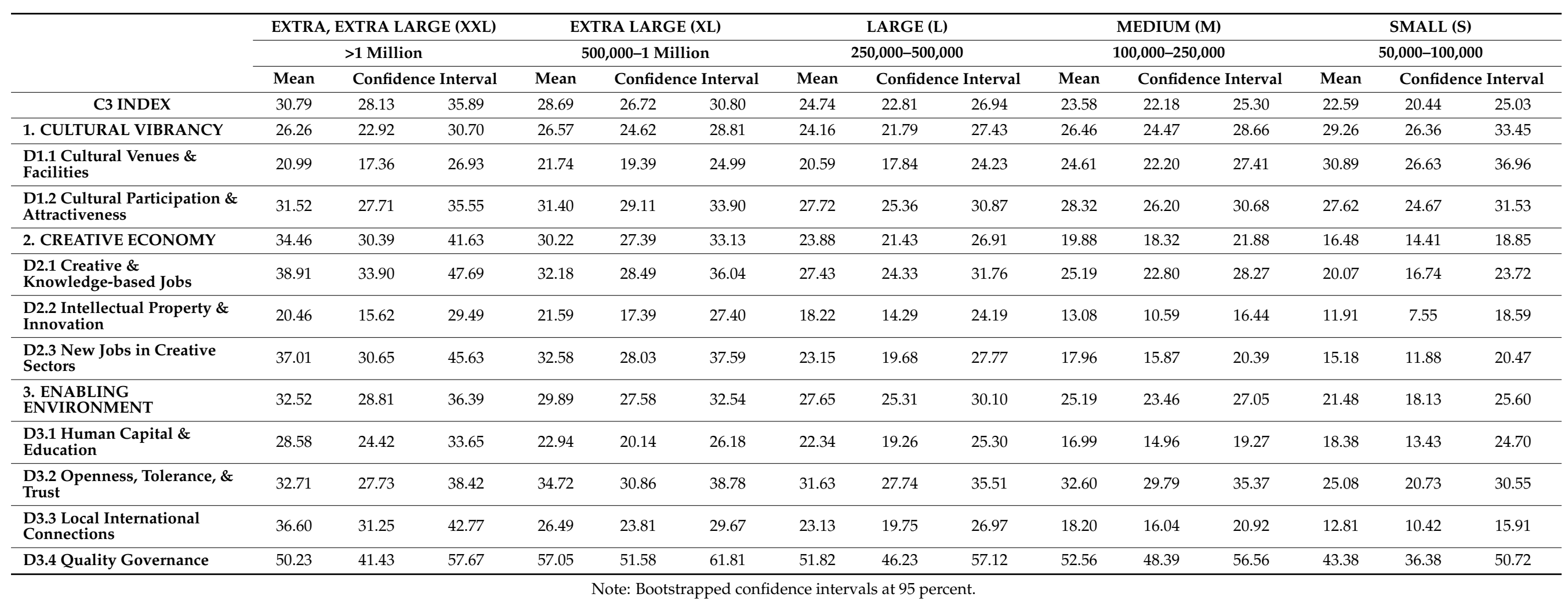


We also detect that the group of small and medium-sized cities present on average statistically equal scores. The bootstrapped confidence intervals overlap for all indicators, except for the dimension "D3.3 Local \& International Connections". This finding supports the merger of the small and medium-sized (S-M) groups made in Montalto et al. [8]. The group of the extra, extra-large cities and the extra-large cities also have similar scores, from a statistical point of view. Thus, it could be possible to consider three different population groups: extra-large cities (population more than 500,000 inhabitants), large cities, and medium-small sized cities (population less than 250,000 inhabitants).

To make a temporal comparison possible, Montalto et al. [8] recalculated the 2017 C3 Index, applying the methodology and data sources used in the 2019 C3 Index. Table 4 shows the mean scores and their respective bootstrapped confidence intervals for the 2017 C3 Index and its components. Comparing Tables 3 and 4, we provide statistical arguments that support the conclusion given in [8]: on average, 2019 scores remain mainly stable compared to 2017. We do not find statistical evidence of significant variations, except for the dimension "D3.4, Quality of Governance". In this case, we detect a pronounced general decline, statistically significant for the extra-large, large, medium, and small city groups.

\subsection{In-Depth Analysis of Results for Small Cities and Their Creative Tourism Development Potential}

As indicated above, small cities mostly perform worse than larger cities in some areas described in the $\mathrm{C} 3$ index. However, they show encouraging results in some items, that suggest important advantages for the development of creative tourism. The strengths and weaknesses detected can give relevant insights for planning adequate strategies and overcoming potential limitations.

Cultural Vibrancy: The smallest cities have higher cultural vibrancy. The Sub-index Cultural Vibrancy score is the result of the weighted average of two equally weighted dimensions: "D1.1 Cultural Venues \& Facilities" and "D1.2 Cultural Participation \& Attractiveness". It approximates the cultural features of a city in terms of cultural infrastructures and participation in culture. We observe that the small cities group (group 5) presents the highest mean for this sub-index (29.26). However, the estimated bootstrapped confidence intervals reveal that the means of the different groups are not statistically significant (all intervals overlap). That is, we cannot reject that the score mean of group 1 (26.26), group 2 (26.57), group 3 (24.16), and group 4 (26.46) are statistically lower than the small cities group (group 5). In spite of the absence of significance, this finding has important implications. The smallest cities have levels of cultural infrastructures and cultural participation at least as good as the big cities. However, we must be cautious about this result; the good performance of the smallest cites may be related to how dimensions D.1.1 and D.1.2 were constructed. These dimensions are constructed by considering indicators per capita. For instance, one of the indicators of dimension D.1.1 is "Theatres": number of theatres in the city divided by the total population and then multiplied by 100,000 . Relativizing in per capita terms could be artificially increasing the scores of the smallest cities.

From the point of view of creative tourism and its cultural dimension, smaller cities have been shown to have a favorable inventory of cultural infrastructures together with higher cultural vibrancy in some cases [8], which can be a powerful magnet for creative travelers. This abundance of already existing resources can offer a solid basis upon which to develop city strategies, progress, and growth. Thoughtful cultural programming can be an excellent way for small cities to be put on the map and avoid copying bigger cities [7]. Cultural events are particularly interesting, as they are highly important resources for creative development everywhere, helping develop economic and cultural links between locations and communities [1]. They provide excellent opportunities for focusing on different cooperative creative networks and all aspects of the tourism industry, offering a perfect connection between creativity and tourism. Likewise, they can increase the possibilities of creative outcomes [23]. Additionally, they can contribute to drawing attention to their city and improving its reputation in collaboration with the entire city, especially entrepreneurs [23]. 
Table 4. Population groups: Average scores and bootstrapped confidence intervals for the 2017 C 3 Index, its sub-indices, and dimensions.

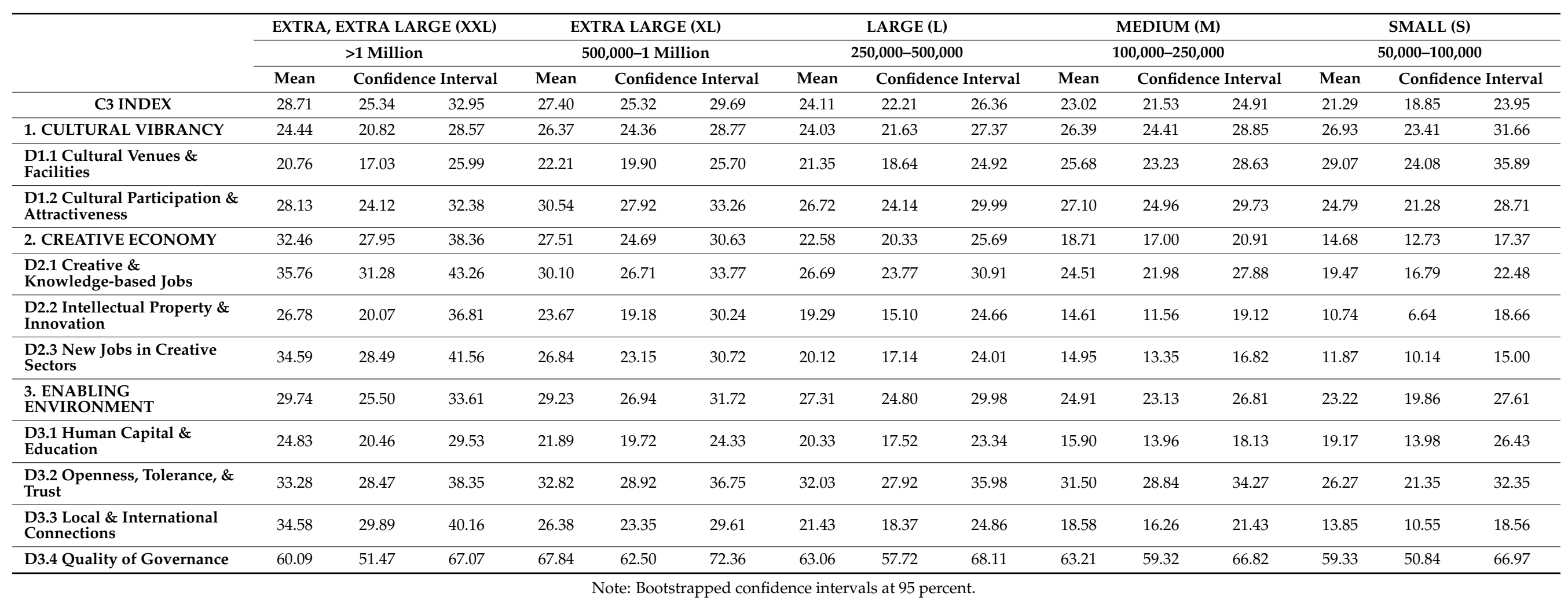


An interesting aspect of creative tourism events is that attendees are usually a combination of residents and tourists; thus, events offer the perfect context for the interaction between the two, becoming the perfect scenario for creative tourism development.

To be successful, it is essential to have collaboration, attention to practical details, a clear vision, and a realistic place-making strategy [23]. Additionally, strong leadership is fundamental for the planning and implementation of creative-based strategies [10] and the promotion of creativity-generating activities, based on tourists becoming fully immersed in some sort of interactive tourism experience [24-26]. In addition to being interactive, experiences need to be authentic [27]. For this reason, tourism providers and local leaders should be aware of the risk of creating new experiential spaces, as they can convey a loss of authenticity and distort the essence of creative tourism experiences [28]. These experiences tend to leave deep imprints on participants and a profound influence on their memories, level of satisfaction, and behavioral intentions (revisit intention and positive word of mouth). If a high-quality experience is provided, tourists are more likely to revisit and recommend the destination [29-31].

When we talk about creative tourism products, it is essential to take into account that in order to be considered creative and effective, the product has to be more than "new"; furthermore, it has to include the different features mentioned earlier, mainly, learning, emotional involvement, interaction, and co-creation [25,32], provided in an authentic atmosphere. The common aim is that the resulting activity becomes a memorable experience for the tourist.

For successful creative experiences, the generated products play an essential role. They can be marketed using specific strategies [33] aimed at making the most of tangible resources, which usually involve the implication of manual activities (cooking, handicrafts) versus intangible resources including inherited expressions and traditions (rituals, social practices, festive events, and so on). Accordingly, creative tourism proposals will frequently depend on the ability of a destination to boost added value to their cultural heritage and natural resources to attract visitors and transform destinations. The prospective actions require a thoughtful analysis of all the elements that come into play to produce something unique, interactive, experiential, and co-creative based on authenticity. To achieve this purpose, both the tangible and intangible aspects of culture must be fully respected [34].

Creative Economy: The more populated the cities, the higher the contribution of cultural and creative sectors to the city economy. The biggest cities in terms of population show a higher and significant score in the sub-index "Creative economy". They are able to generate more employment and innovation.

Regarding the results of the creativity economy indexes, small cities are the ones that present more limitations, but also greater challenges. Research has shown that knowledge and innovation have become decisive competitive factors needed for their transformation into creative cities $[23,35]$. Especially in small places, creativity can be crucial for reviving economies [36], and there is abundant research that corroborates the important link between creative economy and small cities [10]. The economic potential of the tourism industry is indisputable, with a very significant impact on many other sectors. For this reason, creative tourism may be a development tool to foster the creative economy in small town settings. It can become an essential economic driver for the local economy, favoring the entrepreneurial vocation of the population [4], the establishment of start-ups and spinoffs in creative industries [5], and the attraction of lifestyle entrepreneurs [37] who base their activity on their hobbies and interests, generally based on different types of creative products and approaches developed and built upon sharing their knowledge and passion with others $[38,39]$. Creative people settled in small urban areas tend to have a strong entrepreneurial spirit, favoring new cultural, creative businesses and new jobs that, in turn, attract more creative people, associations, and businesses. Thus, they can be valuable agents for job creation and growth in small communities [10]. Additionally, the atmosphere this creates is highly suitable for building the perfect scenario for creative tourism. 
On the other hand, creative tourism offers new possibilities of economic growth by recovering different areas and resources and making destinations more attractive [40]. Likewise, it fosters the use of alternative public spaces as opposed to the most frequently visited landmarks, contributing to the revitalization of other parts of the destinations and controlling overcrowding in emblematic spots. The fact that creative tourism does not necessarily imply the development of significant infrastructure or large investments is of special relevance. New projects are frequently based on exploiting the numerous authentic resources that are available, applying creative formulas in order to attract both professionals from the creative sector and creative tourists in search of stimulating integrative experiences. Thus, creativity dominates the entire process, providing new opportunities for destinations and their residents, helping creative professionals to make a name for themselves, and awakening and fostering tourists' creative potential [34].

Enabling Environment: Big cities have a statistically higher score in the "Enabling Environment" sub-index. That is, the most populated cities (population greater than 500,000 inhabitants) have tangible and intangible assets that statistically attract more creative talent and stimulate cultural engagement to a higher degree than cities with a population below 250,000 inhabitants. Big cities attract significantly more human capital and education, and, above all, they offer much better local and international connections.

Several authors have highlighted the important role of a creative-friendly education system in encouraging creative people to settle down [10] and develop creative minds and talents [41]. According to our results, city size does seem to be significant in education. However, it is worth observing the score and confidence interval associated to the dimension "D.3.1 Human Capital \& Education" for the small cities group: 18.38 and [13.43,24.70]. This score is higher than that corresponding to the group of medium-sized cities (16.99), although it is not statistically higher. The width of the confidence interval for the group of the small cities indicates that there is a high level of heterogeneity within this group. We can find small cities that present an extremely low score (e.g., Pula, Croatia, has a score of 0.35 in dimension D3.1) along with cities with an extremely high score (e.g., Leuven, Belgium, has a score of 56.32 in dimension D3.1). Such a high level of variability may be due to the fact that many small cities have historic iconic universities (Santiago de Compostela, Spain; Coimbra, Portugal; Cambridge, UK; Leuven, Belgium), demonstrating that knowledge, scholarship, and creativity can flourish in small places as well. Today, many small cities have colleges dependent on main universities or newly created universities. Using this knowledge structure to collaborate with other cultural and creative industries, creating ties between higher education and the creative economy [42], may be an effective way to fuel the city's creative potential and generate a vital and stimulating atmosphere that can attract visitors.

For many scholars, there is a clear link between creativity and urban contexts, which significantly attract the so-called creative class [43]. Likewise, tourists perceive creativity more easily in places with a multicultural, diverse, and cosmopolitan atmosphere. Montalto et al. [8] indicate that large cities are the ones that rank higher in the intercultural component associated to creativity. Although our results corroborate this finding, we do not find significant differences in the scores of dimension "D3.2 Openness, Tolerance, and Trust" among the different population groups. Within the context of creative tourism, small cities can be excellent scenarios for creative development as interaction, participation, cooperation, integration, and emotional involvement can naturally occur in smaller places favoring multiculturalism. In this way, creative tourism can foster intercultural exchange and make cities more tolerant [44]. By participating in creative activities, tourists in small cities can have a completely different experience, with the option to be integrated in the daily life, culture, and traditions of their destination. Likewise, tourists have more contact with locals, establishing an enriching participative interaction between both [34]. In the same way, tourism providers and tourists enrolled in creative activities can generate valuable cooperative interactions that contribute to making tourists proactive agents of 
tourism experiences [30]. By sharing their experiences, tourists become part of the host community and have a positive impact on the vitality and ambience of destinations.

Regarding local and international connections, dimension "D3.3 Local \& International Connections", there are significant differences in the performance of cities according to size. Small cities clearly rank lower than bigger cities, so clearly some remedial action could be taken to boost creative tourism development. Small cities have clear disadvantages, as part of their idiosyncrasy lies in their locations in more peaceful and nature-connected areas, far from the fast-paced atmosphere of motorways, high-speed trains, and airports. However, if transport connections are an issue when attracting potential creative entrepreneurs, promoters, and tourists, local authorities should assess the situation and consider adequate strategies to improve them. Local authorities could also try establishing collaborating networks with neighboring cities for educational and cultural facilities [23] or through the integration of international networks such as the UNESCO network of creative cities, which stimulates the economic, cultural, social, and creative development (URBACT) of small cities. This is a specific European program that fosters integrated urban development and favors creative network actions. It is essential for small cities to participate in international networks combining local and global spheres [10]. Collaborating with other cities through the available European networks is fundamental for stimulus and success [7,45].

According to the scores and bootstrapping results for dimension "D3.4 Quality of Governance", quality of governance is not one of the strengths of small cities, but their performance is not worse than medium, large, and extra, extra-large cities, which indicates the commitment of local authorities. The governance dimension is fundamental for small creative cities, and local policies should provide specific infrastructures and support schemes to attract creative people [10] and foster creativity in the knowledge economy, always in close collaboration with local parties [23]. On the other hand, there should be a specific local policy that favors the collaboration and cooperation with creative tourism promoters, as its absence may constitute a limitation for creative tourism development [46]. Authorities should be aware of the creative potential, uniqueness, and assets of their cities and avoid the standardization of urban development [47]. On the contrary, they should base their public policies on new challenges, strategies, and measures [48] and define context-specific policies adapted to their precise situation [10]. Hence, local leadership is fundamental to promote creativity-based strategies [41].

Although the cities' living conditions and quality of life have not been included in the final version of the C3 Index, it is important to emphasize their relevance in the case of small cities. The developers of the C3 Index also considered different indicators to approximate cities' living conditions and quality of life, such as the number of dwellings lacking basic amenities or the average indicators, which were not retained because of problems they displayed: they did not fit in the overall framework based on theoretical considerations and/or in the statistical analysis, or they presented poor data coverage. The higher quality of life there can attract the creative class and artists to start and bring up their families, attracted by a pleasant atmosphere and good access to knowledge and culture [7,49]. Quality of life, based on competitive advantages such as well-being, sustainability, and social inclusion, is a very important characteristic defining small cities. This combination of social, cultural, and environmental assets appeals to creative people and entrepreneurs, who are attracted by a more balanced and inspiring work-life relationship [10,50]. Their presence will contribute to transform the city and become part of their creative evolution. Local authorities can bring about quite a change to channel creative people's desire for more adequate places to develop their projects by facilitating and supporting infrastructures for entrepreneurship, frequently linked to under-utilized historical and industrial heritage [10]. The resulting creative, stimulating atmosphere will equally appeal to creative travelers.

\section{Conclusions}

Most researchers agree on the fact that one of the risks of small cities' strategies to become more creative and attract visitors is the attempt to emulate successful large cities. The first implication that we can extract from the use of bootstrapping techniques on the $\mathrm{C} 3$ 
Index is that small cities have distinct strengths and weaknesses that require specific and focused strategic planning. Small cities should adopt more strategic place-making approaches that engage all stakeholders [7]. There is an important contrast between globalization (and the process of homogenization it conveys) and the uniqueness of places. Cities should learn to abandon this dangerous track and rely on their specific local characteristics [51] to highlight their excellence and establish differentiation from others, which requires creative approaches to overtake their competitors [23]. Creative cities should be developed with their existing, historically developed urban environment [23] taken into account, as well as their unique tangible and intangible resources [7], and avoid homogenization [52], copycat behavior [53], or serial reproduction [54].

From the point of view of tourism, one of the main challenges is to control the increase of creative tourism development and the vulnerability of local culture [55]. Equally, the risk of the commodification of everyday life, gentrification, the displacement of communities, passive consumption, and overcrowding need to be addressed [9]. Due to the characteristics of creative tourism and its unique features, difficult to be adapted to other places, it is rather unlikely that this might happen; unfortunately, careless planning and a lack of control can produce undesirable results [9].

A place is only creative when recognized as such by the outside world. The image of a place conditions the decision to settle down. A key concept is to be known and noticed [7]. This is determined by its history and marketing strategies (city marketing or branding). In this sense, developing a strong brand that emphasizes their local conditions and traditions is essential [23]. Otherwise, in addition to lower competitiveness, it might have to face rejection from locals. If the idiosyncrasy of the city and its inhabitants is lost, initiatives can encounter opposition and rejection. To succeed, city marketing should consider a balance between identity, image, and the desired reputation [23]. However, the brand will not work unless it is backed up by reality; thus, cities should focus their efforts on increasing their appeal and continuing to improve their reality [56]. By doing so, they will have a better image and will attract more visitors and potential residents and investors [55].

To be successful, small creative cities that want to be placed on the map and develop creative tourism-based strategies have proven to have some features in common: a specific focus on their local environment, endogenous amenities based on their natural and built environment, a strong sense of community, and a good quality of governance that fosters and supports infrastructures for entrepreneurship and creative activities [10]. The construction of bootstrapped confidence intervals for the C3 Index's scores suggests that small cities have enormous potential for the development of creative tourism, thanks to their specific unique features and resources. This can result in an improved economic situation and more creativity-based jobs, thanks to creative entrepreneurs attracted to small cities (increase in the last two years, according to the C3 Index). In turn, this tool has helped flag certain limitations for balanced intercultural interaction. In this respect, thanks to its interactive and integrative character, creative tourism could help improve cities' openness and tolerance dimension and contribute to their growth and quality of life.

Author Contributions: Conceptualization: M.M., E.d.P.C. and M.Á.-D.; formal analysis: M.M.; investigation: M.M., E.d.P.C. and M.Á.-D.; methodology: M.Á.-D.; software: M.Á.-D.; supervision: M.M., E.d.P.C. and M.Á.-D.; validation: M.M. and E.d.P.C.; writing-original draft: E.d.P.C. and M.Á.-D.; writing—review and editing: E.d.P.C. All authors have read and agreed to the published version of the manuscript.

Funding: This research received no external funding.

Informed Consent Statement: Not applicable.

Data Availability Statement: Publicly available datasets were analyzed in this study. These data can be found here: https: / / composite-indicators.jrc.ec.europa.eu/cultural-creative-cities-monitor/docsand-data (accessed on 24 November 2020).

Conflicts of Interest: The authors declare no conflict of interest. 


\section{Appendix A}

Table A1. GDP per capita groups: Average scores and bootstrapped confidence intervals for the 2019 C3 Index, its sub-indices and dimensions.

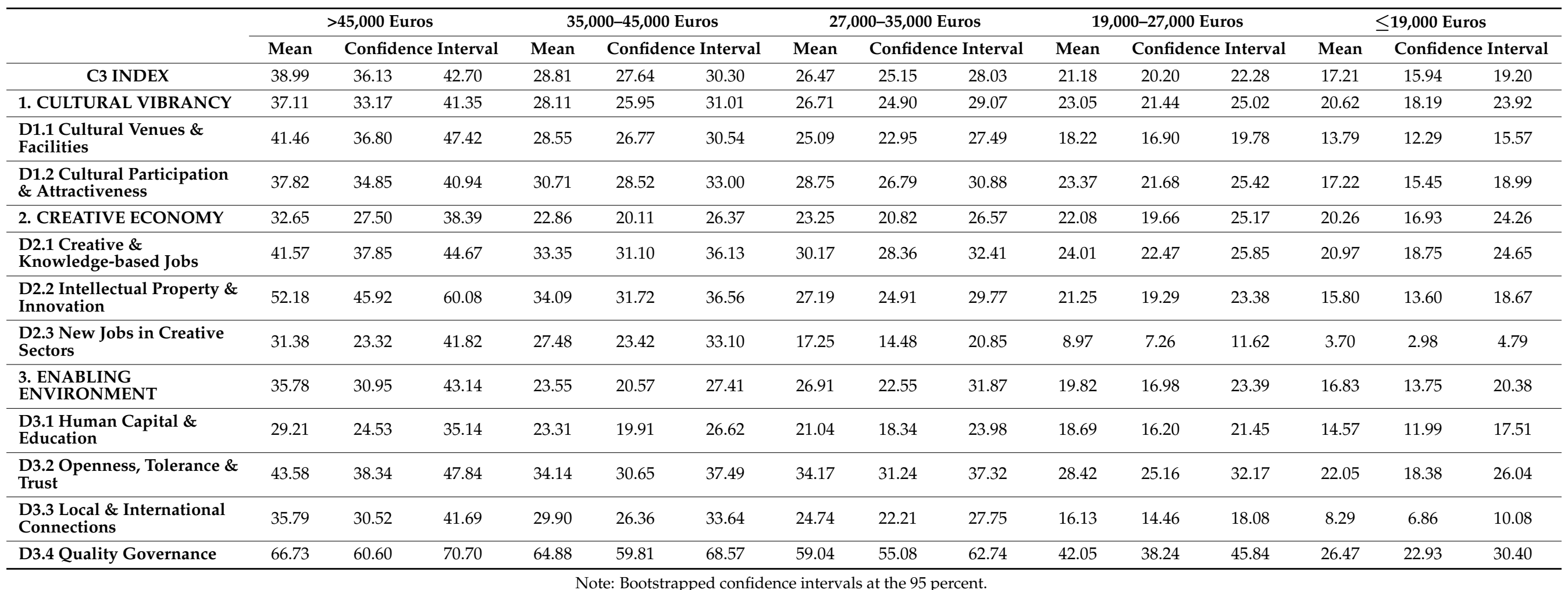


Table A2. Employment rate groups: Average scores and bootstrapped confidence intervals for the 2019 C3 Index, its sub-indices and dimensions.

\begin{tabular}{|c|c|c|c|c|c|c|c|c|c|c|c|c|c|c|c|}
\hline \multirow[b]{3}{*}{ C3 INDEX } & \multicolumn{3}{|c|}{$>79 \%$} & \multicolumn{3}{|c|}{$75-79 \%$} & \multicolumn{3}{|c|}{$70-75 \%$} & \multicolumn{3}{|c|}{$63-70 \%$} & \multicolumn{3}{|c|}{$\leq 63 \%$} \\
\hline & \multirow{2}{*}{$\begin{array}{c}\text { Mean } \\
32.94\end{array}$} & \multicolumn{2}{|c|}{ Confidence Interval } & \multirow{2}{*}{$\begin{array}{c}\text { Mean } \\
26.86\end{array}$} & \multicolumn{2}{|c|}{ Confidence Interval } & \multirow{2}{*}{$\begin{array}{c}\text { Mean } \\
25.77\end{array}$} & \multicolumn{2}{|c|}{ Confidence Interval } & \multirow{2}{*}{$\begin{array}{c}\text { Mean } \\
22.24\end{array}$} & \multicolumn{2}{|c|}{ Confidence Interval } & \multirow{2}{*}{$\begin{array}{c}\text { Mean } \\
20.30\end{array}$} & \multicolumn{2}{|c|}{ Confidence Interval } \\
\hline & & 30.82 & 35.14 & & 25.33 & 28.29 & & 23.69 & 28.56 & & 21.02 & 23.91 & & 18.94 & 21.78 \\
\hline 1. CULTURAL VIBRANCY & 29.14 & 26.73 & 32.12 & 24.01 & 22.38 & 25.63 & 27.81 & 24.83 & 31.32 & 24.53 & 22.67 & 27.07 & 25.52 & 23.32 & 28.08 \\
\hline $\begin{array}{l}\text { D1.1 Cultural Venues \& } \\
\text { Facilities }\end{array}$ & 36.74 & 33.85 & 39.55 & 28.40 & 26.20 & 30.64 & 22.94 & 20.59 & 26.85 & 19.44 & 18.06 & 20.92 & 14.05 & 12.85 & 15.50 \\
\hline $\begin{array}{l}\text { D1.2 Cultural Participation } \\
\text { \& Attractiveness }\end{array}$ & 32.94 & 30.16 & 35.79 & 29.48 & 26.93 & 31.96 & 27.35 & 25.16 & 29.65 & 23.26 & 21.09 & 25.83 & 22.35 & 20.14 & 24.92 \\
\hline 2. CREATIVE ECONOMY & 23.17 & 20.48 & 26.85 & 19.17 & 17.30 & 21.70 & 24.38 & 20.97 & 28.46 & 23.22 & 20.72 & 26.39 & 27.13 & 23.71 & 31.41 \\
\hline $\begin{array}{l}\text { D2.1 Creative \& } \\
\text { Knowledge-based Jobs }\end{array}$ & 35.11 & 32.41 & 38.14 & 28.85 & 27.02 & 30.69 & 31.23 & 28.21 & 34.63 & 25.85 & 23.87 & 28.25 & 23.91 & 22.09 & 26.20 \\
\hline $\begin{array}{l}\text { D2.2 Intellectual Property \& } \\
\text { Innovation }\end{array}$ & 39.49 & 35.69 & 44.58 & 28.70 & 25.35 & 31.98 & 28.17 & 24.61 & 33.04 & 24.98 & 22.08 & 28.40 & 19.49 & 17.64 & 21.79 \\
\hline $\begin{array}{l}\text { D2.3 New Jobs in Creative } \\
\text { Sectors }\end{array}$ & 29.17 & 22.80 & 36.95 & 19.43 & 15.84 & 24.16 & 16.75 & 13.80 & 20.58 & 10.03 & 8.29 & 12.78 & 8.41 & 5.74 & 13.49 \\
\hline $\begin{array}{l}\text { 3. ENABLING } \\
\text { ENVIRONMENT }\end{array}$ & 37.78 & 33.81 & 41.82 & 32.59 & 27.59 & 38.29 & 20.80 & 17.87 & 25.18 & 18.59 & 16.03 & 22.02 & 11.42 & 10.16 & 13.22 \\
\hline $\begin{array}{l}\text { D3.1 Human Capital \& } \\
\text { Education }\end{array}$ & 23.84 & 20.89 & 26.78 & 21.80 & 18.65 & 24.86 & 21.44 & 18.43 & 24.87 & 16.56 & 13.51 & 20.33 & 20.17 & 16.66 & 24.14 \\
\hline $\begin{array}{l}\text { D3.3 Local \& International } \\
\text { Connections }\end{array}$ & 31.27 & 26.86 & 36.06 & 24.14 & 21.05 & 27.78 & 22.94 & 19.88 & 26.53 & 20.05 & 16.99 & 23.73 & 13.78 & 11.76 & 16.25 \\
\hline D3.4 Quality Governance & 65.30 & 59.96 & 69.28 & 59.13 & 53.32 & 64.02 & 51.46 & 46.69 & 55.72 & 47.07 & 41.78 & 52.34 & 37.86 & 32.74 & 43.64 \\
\hline
\end{tabular}


Table A3. Regional development groups: Average scores and bootstrapped confidence intervals for the 2019 C3 Index, its sub-indices and dimensions.

\begin{tabular}{|c|c|c|c|c|c|c|c|c|c|}
\hline \multirow[b]{3}{*}{ C3 INDEX } & \multicolumn{3}{|c|}{ More Developed } & \multicolumn{3}{|c|}{ Transition Regions } & \multicolumn{3}{|c|}{ Less Developed } \\
\hline & \multirow{2}{*}{$\begin{array}{c}\text { Mean } \\
28.16\end{array}$} & \multicolumn{2}{|c|}{ Confidence Interval } & \multirow{2}{*}{$\begin{array}{c}\text { Mean } \\
22.30\end{array}$} & \multicolumn{2}{|c|}{ Confidence Interval } & \multirow{2}{*}{$\begin{array}{r}\text { Mean } \\
19.45\end{array}$} & \multicolumn{2}{|c|}{ Confidence Interval } \\
\hline & & 27.10 & 29.45 & & 19.99 & 25.24 & & 18.28 & 20.77 \\
\hline 1. CULTURAL VIBRANCY & 28.18 & 26.86 & 29.75 & 25.87 & 22.78 & 31.24 & 20.40 & 18.85 & 22.27 \\
\hline D1.1 Cultural Venues \& Facilities & 26.80 & 25.16 & 28.83 & 18.31 & 15.94 & 21.81 & 18.51 & 16.60 & 20.77 \\
\hline $\begin{array}{l}\text { D1.2 Cultural Participation \& } \\
\text { Attractiveness }\end{array}$ & 30.83 & 29.33 & 32.38 & 23.14 & 20.38 & 26.05 & 19.41 & 18.09 & 20.62 \\
\hline D2.1 Creative \& Knowledge-based Jobs & 31.53 & 30.10 & 33.16 & 27.11 & 24.21 & 30.95 & 22.63 & 20.77 & 24.82 \\
\hline D2.2 Intellectual Property \& Innovation & 31.90 & 30.03 & 34.16 & 22.61 & 19.79 & 25.32 & 17.68 & 15.56 & 20.30 \\
\hline D2.3 New Jobs in Creative Sectors & 21.54 & 18.96 & 24.83 & 12.40 & 7.88 & 18.95 & 7.26 & 5.81 & 9.55 \\
\hline 3. ENABLING ENVIRONMENT & 24.33 & 21.94 & 27.22 & 16.98 & 13.04 & 23.99 & 24.96 & 21.16 & 29.33 \\
\hline D3.1 Human Capital \& Education & 23.10 & 21.08 & 25.20 & 17.20 & 13.38 & 21.84 & 17.39 & 15.13 & 19.79 \\
\hline D3.2 Openness, Tolerance \& Trust & 35.86 & 33.66 & 38.07 & 27.68 & 23.38 & 32.93 & 23.35 & 20.46 & 26.41 \\
\hline D3.4 Quality Governance & 60.86 & 57.97 & 63.51 & 47.38 & 41.07 & 53.16 & 31.62 & 28.58 & 34.53 \\
\hline
\end{tabular}

Note: Bootstrapped confidence intervals at the 95 percent. 


\section{References}

1. Richards, G. Creativity and tourism: The state of the art. Ann. Tour. Res. 2011, 38, 1225-1253. [CrossRef]

2. Richards, G.; Raymond, C. Creative tourism. ATLAS News 2000, 23, 16-20.

3. Huang, Y.C.; Chang, L.L.; Backman, K.F. Detecting common method bias in predicting creative tourist behavioural intention with an illustration of theory of planned behaviour. Curr. Issues Tour. 2019, 22, 307-329. [CrossRef]

4. Lima, F.B.C.; e Silva, Y.F. "Project Querença" and creative tourism: Visibility and local development of a village in the rural Algarve. eRTR 2017, 14, 21-35.

5. Dzupka, P.; Sebova, M. Local economic impact of the WHITE night festival in Kosice. E M Ekon. Manag. 2016, 19, 132-142.

6. Richards, G. Creative tourism: Opportunities for smaller places? Tour. Manag. Stud. 2019, 15, 7-10. [CrossRef]

7. Richards, G.; Duif, L. Small Cities with Big Dreams: Creative Placemaking and Branding Strategies; Routledge: New York, NY, USA, 2018.

8. Montalto, V.; Moura, C.J.T.; Alberti, V.; Panella, F.; Saisana, M. The Cultural and Creative Cities Monitor, 2019 ed.; Publications Office of the European Union: Luxembourg, 2019.

9. Keller, I.I.; Velibeyoğlu, K. The rise and fall of the rural creative class: The case of Alaçatı. City Cult. Soc. 2021, 24, 100372. [CrossRef]

10. Selada, C.; Cunha, I.V.D.; Tomaz, E. Creative-based strategies in small cities: A case-study approach. Redige 2011, 2, 79-111.

11. Nardo, M.; Saisana, M.; Saltelli, A.; Tarantola, S.; Hoffman, A.; Giovannini, E. Handbook on Constructing Composite Indicators: Methodology and User Guide; OECD Publishing: Paris, France, 2008.

12. Montalto, V.; Moura, C.J.T.; Langedijk, S.; Saisana, M. Culture counts: An empirical approach to measure the cultural and creative vitality of European cities. Cities 2019, 89, 167-185. [CrossRef]

13. Stipanović, C.; Rudan, E.; Zubović, V. Cultural and creative industries in urban tourism innovation-The example of the city of Rijeka. In Creating Innovative Tourism Experiences: The Way to Extend the Tourist Season, Proceedings of the 5th International Scientific Conference Tourism in Southern and Eastern Europe 2019, Opatija, Croatia, 16-18 May 2019; University of Rijeka, Faculty of Tourism and Hospitality Management: Opatija, Croatia, 2019; Volume 5, pp. 655-666.

14. Montalto, V.; Panella, F.; Sacco, P.L. What does Brexit mean for UK cultural and creative cities? Eur. Urban Reg. Stud. 2020, 28, 47-57. [CrossRef]

15. De Jorge-Moreno, J.; De Jorge-Huertas, V. Measuring European cultural and creative cities efficiency: A metafrontier DEA approach. J. Econ. Stud. 2020, 47, 891-909. [CrossRef]

16. Van Puyenbroeck, T.; Montalto, V.; Saisana, M. Benchmarking culture in Europe: A data envelopment analysis approach to identify city-specific strengths. Eur. J. Oper. Res. 2021, 288, 584-597. [CrossRef]

17. DiCiccio, T.J.; Efron, B. Bootstrap confidence intervals. Stat. Sci. 1996, 11, 189-228. [CrossRef]

18. Briggs, A.H.; Wonderling, D.E.; Mooney, C.Z. Pulling cost-effectiveness analysis up by its bootstraps: A non-parametric approach to confidence interval estimation. Health Econ. 1997, 6, 327-340. [CrossRef]

19. Brownstone, D.; Valletta, R. The bootstrap and multiple imputations: Harnessing increased computing power for improved statistical tests. J. Econ. Perspect. 2001, 15, 129-141. [CrossRef]

20. Martínez, W.; Martínez, A.R. Computational Statistics Handbook with MATLAB; Chapman \& Hall/CRC: Boca Ratón, FL, USA, 2008

21. Mooney, C.Z.; Duval, R.D. Bootstraping: A nonparametric Approach to Statistical Inference. SAGE University Paper Series on Quantitative Applications to Social Sciences; Series No. 07-095; Sage: Newbury Park, CA, USA, 1993.

22. Efron, B.; Tibshirani, R.J. An Introduction to the Bootstrap; Chapman \& Hall: Boca Raton, FL, USA, 1998.

23. Hospers, G.J. Creative cities: Breeding places in the knowledge economy. Knowl. Technol. Policy 2003, 16, 143-162. [CrossRef]

24. Binkhorst, E. Creativity in tourism experiences: The case of Sitges. In Tourism, Creativity and Development; Richards, G., Wilson, J., Eds.; Routledge: London, UK, 2007; pp. 124-144.

25. Hung, W.L.; Lee, Y.J.; Huang, P.H. Creative experiences, memorability and revisit intention in creative tourism. Curr. Issues Tour. 2016, 19, 763-770. [CrossRef]

26. Tan, S.K.; Kung, S.F.; Luh, D.B. A model of 'creative experience' in creative tourism. Ann. Tour. Res. 2013, 41, 153-174. [CrossRef]

27. Chronis, A.; Hampton, R.D. Consuming the authentic Gettysburg: How a tourist landscape becomes an authentic experience. J. Consum. Behav. 2008, 7, 111-126. [CrossRef]

28. Fawcett, C.; Cormack, P. Guarding authenticity at literary sites. Ann. Tour. Res. 2001, 28, 686-704. [CrossRef]

29. Ali, F.; Ryu, K.; Hussain, K. Influence of experiences on memories, satisfaction and behavioral intentions: A study of creative tourism. J. Travel Tour. Mark. 2016, 33, 85-100. [CrossRef]

30. Hurriyati, R.; Sofwan, D.M.P. Analysis of co-creation experience towards a creative city as a toursim destination and its impact on revisit intention. J. Environ. Manag. Tour. 2015, 6, 353-364.

31. Suhartanto, D.; Brien, A.; Primiana, I.; Wibisono, N.; Triyuni, N.N. Tourist loyalty in creative tourism: The role of experience quality, value, satisfaction, and motivation. Curr. Issues Tour. 2019, 23, 1-13. [CrossRef]

32. Ali, F.; Hussain, K.; Ragavan, N.A. Memorable customer experience: Examining the effects of customers experience on memories and loyalty in Malaysian resort hotels. Proced. Soc. Behav. 2014, 144, 273-279. [CrossRef]

33. Ross, D.; Saxena, G.; Correia, F.; Deutz, P. Archaeological tourism: A creative approach. Ann. Tour. Res. 2017, 67, 37-47. [CrossRef] 
34. De Prada, E.; Mareque, M. Tourism. In Encyclopedia of Creativity, 3nd ed.; Pritzker, S.R., Runco, M.A., Eds.; Academic Press/Elsevier: Cambridge, MA, USA, 2020; Volume 2, pp. 649-656.

35. Landry, C. The Creative City: A Toolkit for Urban Innovators; Earthscan: London, UK, 2000.

36. Petrov, A. A look beyond metropolis: Exploring creative class in the Canadian periphery. Can. J. Reg. Sci. 2007, 30, 451-474.

37. Peters, M.; Frehse, J.; Buhalis, D. The importance of lifestyle entrepreneurship: A conceptual study of the tourism industry. PASOS 2009, 7, 393-405. [CrossRef]

38. Marchant, B.; Mottiar, Z. Understanding Lifestyle Entrepreneurs and Digging Beneath the Issue of Profits: Profiling Surf Tourism Lifestyle Entrepreneurs in Ireland. Tour. Plan. Dev. 2011, 8, 171-183. [CrossRef]

39. Smith, M.; Puczkó, L. Health and Wellness Tourism; Routledge: London, UK, 2008.

40. Hannigan, J. From fantasy city to creative city. In Tourism, Creativity and Development; Richards, G., Wilson, J., Eds.; Routledge: London, UK, 2007; pp. 48-56.

41. Sdrali, D. Creative Strategies for Sustainable Development in Small Cities. In Decent Work and Economic Growth; Springer: Cham, Switzerland, 2020.

42. Comunian, R.; Gilmore, A. Higher Education and the Creative Economy: Beyond the Campus; Routledge: New York, NY, USA, 2016.

43. Florida, R. The Rise of the Creative Class; Basic Books: New York, NY, USA, 2002.

44. Blapp, M.; Mitas, O. Creative tourism in Balinese rural communities. Curr. Issues Tour. 2018, 21, 1285-1311. [CrossRef]

45. Arandelovic, B. Graz, UNESCO city of design and historical heritage. Cities 2015, 43, 78-91. [CrossRef]

46. Dias-Sardinha, I.; Ross, D.; Calapez Gomes, A. The clustering conditions for managing creative tourism destinations: The Alqueva region case, Portugal. J. Environ. Plan. Manag. 2018, 61, 635-655. [CrossRef]

47. Munoz, P. Beyond talent, Diversity and Technology: Transforming Small Cities into Creative Places. Msc Innovation, Creativity and Entrepreneurship. Newcastle University. 2010. Available online: https:/ /ssrn.com/abstract=2005756 (accessed on 16 January 2021).

48. Van Heur, B. Small cities and the socio spatial specificity of economic development. In Cultural Political Economy of Small Cities; Lorentzen, A., Van Heur, B., Eds.; Routledge: London, UK, 2012; pp. 17-30.

49. Capel, H. Small cities in generalized urbanization and global crisis. Investig. Geogr. 2009, 70, 7-32.

50. Van Oort, F.; Weterings, A.; Verlinde, H. Residential amenities of knowledge workers and the location of ICT-FIrms in the Netherlands. Tijdschr. Econ. Soc. Geogr. 2003, 94, 516-523. [CrossRef]

51. Storper, M. Globalization, Localization and Trade. In The Oxford Handbook of Economic Geography; Clark, G.L., Feldman, M.P., Gertler, M.S., Eds.; Oxford University Press: Oxford, MS, USA, 2000; pp. 146-165.

52. Edensor, T. Staging tourism: Tourists as performers. Ann. Tour. Res. 2000 27, 322-344.

53. Hospers, G.J.; Beugelsdijk, S. Regional cluster policies: Learning by comparing? KYKLOS Int. Rev. Soc. Sci. 2002, 55, 381-402. [CrossRef]

54. Richards, G.; Wilson, J. Developing creativity in tourist experiences: A solution to the serial reproduction of culture? Tour. Manag. 2006, 27, 1209-1223. [CrossRef]

55. Richards, G. Making places through creative tourism. In Cultural Sustainability, Tourism and Development: (Re)Articulations in Tourism Contexts; Duxbury, N., Ed.; Routledge: London, UK, 2021; pp. 36-48.

56. Hildreth, J. The European City Brand Barometer-Revealing Which Cities Get the Brands They Deserve; Saffron Brand Consultants: London, UK, 2008; Volume 1, pp. 2-13. 